elder Marcet, as components of stone, attracted the attention of physicians to the composition and chemical changes taking place in urine. As the substances above-named were found to be frequently formed in excess in the system, it was conjectured that they were eliminated in such quantities by the urine as to be precipitated in the urinary passages. If the passages were free, the deposit passed away as gravel; if the passages were blocked with blood, mucus, epithelium, or otherwise obstructed, the deposit was retained and a calculus was the result.

The view that urinary calculi are the result of a peculiar diathesis wherein uric acid, oxalic acid, or the phosphates are formed in excess in the system, and, in consequence of being eliminated in such quantities by the urine they are precipitated, and perchance retained, in the urinary passages, is still maintained by many writers. The objections that can be urged against the general acceptance of the view are-1. The urinary constituents are not necessarily deposited from urine when they are in excess; a change in the normal reaction of the urine is required to ensure precipitation, and when this change takes place the substances are precipitated whether they are in excess or not. 2 . The particles that form the nucleus of a calculus are not mere accretions formed by a process of rapid precipitation, but consist of granules, spheroids, laminæ, \&c.; structures which have been designated "submorphous," and which have required considerable time for their formation.* 3 . The blocking of the urinary passages with blood, mucus, \&c., is not sufficient to produce a calculus; for if so, stone, instead of being a comparatively rare disease, would be fearfully common, and every attack of gravel would be fraught with danger. Again, obstruction of the urinary passages and retention of the urinary constituents frequently occur in certain chronic kidney diseases, as Bright's disease, hydronephrosis, \&c., yet calculous deposit is rarely an accompaniment of these diseases. Moreover, if renal calculi were caused by retention of precipitated urinary constituents, the deposit would be frequently met with in the convoluted portion of the tubule, for there the greatest obstruction exists to the onward passage of the precipitated matters, but calculi are never found in this portion of the kidney.

The researches of Rainey, + Ord $\$$, and Carter $\S$, show that the urinary constituents forming the nucleus of a calculus have lost their crystalline character, and assume the form of granules, spheroids, \&c. This modification of form can be artificially produced by allowing two saline solutions slowly to intermix through a colloid medium, as gum, albumen, \&c. If the admixture be effected slowly in a dense colloid the globules are more perfect; if, on the other hand, the colloid medium be attenuated, and the admixture rapid, the crystalline form is more or less retained. These researches lead to the conclusion that in order to produce a calculus the urinary passages must furnish a colloid medium, the " entangling mucus" of the old authors. It has been noticed how very infrequent an accompaniment stone is of Bright's disease, when it would naturally be expected that the urinary passages would abound with colloid material in the form of albumen, effused fibrin, casts, \&c., and consequently it has been assumed that the viscid mucus must be furnished by a specific local catarrh. Thus Meckel speaks of a stone-forming catarrh (stein bildenden catarrh), of which the product is calcium oxalate. Dr. Owen Rees | has pointed out that among the evils attendant on gout is a tendency of the mucous membranes to secrete a viscid mucus which modifies the ordinary crystalline character of uric acid, causing it to appear in agglutinated masses which adhere to the sides of the urinary passages. Undoubtedly many renal calculi originate in this manner still calculus frequently occurs in persons who have not, or never have had, renal catarrh, gonty or otherwise.

In order to account for the origin of those calculi not explained by the preceding views, the hypothesis, originally suggested by Professor Quekett, of a calculous degeneration must be resorted to. In this case the deposit does not take place in the cavities of the urinary passages, but originates

* H. Vandyke Carter, M.D., on the Microscopic Structure and Mode of Formation of Urinary Calculi. London, 1873.

On the Formation of Shelle, by $\mathbf{G}$. Rainey, Esq. 1858

$\ddagger$ On Molecular Coalescence, by W. M. Ord, M.B. Quarterly Journal of Microscopic Science, new series, 1872.

Op. cit., pp. 34 and 35.

Uf On Calculous Disease (Gulstonian Lectures), by G. Owen Rees, M.D., F.R.S. London, 1856 . primarily in the cells forming the walls of the tubules themselves. These cells normally eliminate the urinary constituents, and it is not difficult to imagine that under certain conditions of vital impairment these substances may be retained and deposited instead. The conditions that would give rise to such impairment or degeneration are those which would tend to produce atrophic and retrogressive changes in a part, or interfere with the circulation in it. The following considerations will show how such conditions may be brought about.

1. Calculous deposit, when met with in the kidney, invariably occurs at the apices of the mamillary processes, the extremity of the ducti papillares.* Now, less blood circulates through this portion of the kidney than through any other part of it ; $\dagger$ moreover, in the ducti papillares the basement membrane (tunica propria) disappears, and the wall consists of epithelium alone. May not these anatomical differences account for the occurrence of a calculous degeneration at this part of the tubule?

2. Quekett $\ddagger$ has shown that in birds and reptiles the semi-solid uric acid exists in the secreting cells of the kidney, and he has figured crystals of calcium oxalate and triple phosphate contained in cells taken from human tubuli uriniferi, which prove that under certain circumstances these substances are retained and deposited in the human renal cells.

3. Calculous disease is most frequent during the periods of childhood, early youth, and old age, $\S$ periods when the tissues, either from rapidity of growth or general impairment of vitality, are most likely to undergo atrophic and degenerative changes. Calculi also occur frequently after some exhaustive illness, as typhoid, ague, cholera, \&c., in which the vital powers have been considerably lowered. Blows on the loins, violent strains on the back, \&c., are often followed by renal calculi, which, in the absence of any constitutional diathesis, or evidence of hæmic origin, may, $I$ think, fairly be attributed to a calculous degeneration brought about by impairment of the nutrition of the kidney consequent on the injury.

The preceding observations are, necessarily, brief and condensed. I hope, however, I have indicated fairly the work already done, and the work that remains to be done the doubts to be cleared, and the antagonistic points to be settled. Finally, I would suggest that careful microscopic examination should be made of the tubuli uriniferi of persons dying from calculous affections, in order to ascertain, as far as possible, the probable nature of the local mischief that undoubtedly plays the essential part in the origin of calculi. Queen Anne-street, w.

A CASE OF

\section{SUDDEN DEATH FROM EMBOLISM IN} THE INFERIOR VENA CAVA,

IN CONNEXION WITH VARICOSE VEINS OF THE LEG.

BY SURG. THOMAS BROWNE, M.D., H.M. DOCKYARD, DEYONPORT.

(Communicated by the Director-Genkral of the Medicax Departurext OF THE NAVY.)

E. L- a - aged fifty-one, presented himself at the surgery on Jan. 5th with a contusion of the right leg, lower third, inner and posterior aspect, received whilst engaged on duty in H.M.S. Fantome. There was slight ecchymosis, but the injury seemed unimportant. On the same leg a number of varicose veins existed, for which an elastic stocking was recommended. As he complained of pain in the leg on the day following the injury, and the veins aeemed more prominent and knotted, he was recommended rest in the horizontal position. He expressed a strong wish to continue on * In the Hunterian Museum at Glasgow there are specimens showing
this part of the tubuli blocked with calculous deposit, in some cases projecting into the infundibulum, as if ready to drop into the pelvis of the kidney.

$\dagger$ Stricker's Manual of Human and Comparative Histology ; article Kidney, by C. Ludwig.

Lectures on Histology, by J. T. Quekett, Med. Times, 1851.

The renal calculi that result from blows on the loin, \&c., are usually of calcium oxalate, and often attain an enormous size, growing as it were at the expense of the kidney texture. 
duty till the mester rigger, whose place he temporarily filled, should return from leave. On Jan. 9th, the master rigger having returned to duty, E. L- was placed on the sick list for the purpose of securing a few days' rest. There was very little discoloration over the site of the contusion, and, as the injury appeared most trivial, he was entered on the list under the heading "varix." He was recommended a week's rest, and requested to report himself at the surgery at the end of that time, if able to do so.

On Jan. 19th he showed himself, looking and feeling well, stated that his leg was much better, and that he could walk with only trifling discomfort. The veins were less swollen and knotted; slight discoloration atill remained at the site of the contusion, where some thickening and hardening of the skin and tissues beneath were also felt. He expressed himself as feeling well, but would like to remain on the list for a day or two longer, to get accustomed to the elastic stocking which he had worn for a few days. He left the surgery, and in walking down the dockyard was overtaken by a shower, and began to run for shelter. Almost immediately a feeling of faintness came over him; he stopped running, and with difficulty, walking, reached an office close by. Here he threw himself into a chair, anã asked for water, saying he had been taken suddenly ill. He was seen almost immediately by the surgeon, who found him gasping for breath, the air entering and jeaving the lungs freely; his pulse was weak, fluttering, without volume, and intermittent. He was at once placed on his back on the floor, every article of clothing loosened, water sprinkled on his face, the door and windows being in the meantime widely opened. An ounce of brandy was then administered, with water. He was quite sensible, and gave a clear account of how he was taken ill on his way from the surgery, stated that he had no pain, but felt a tightness about the upper and left side of chest. $A s$ in the course of the next fer minutes no improvement took place, the staff surgeon, Dr. Saunders, was communicated with. On his arrival the condition was unchanged, the pulse became weaker, and for a short time imperceptible, and then gradually recovered a little, though still weak, fluttering, and intermittent. The lips and ears became blue, and the face assumed a pinched appearance. He called hastily for the bedpan, but nothing passed from the bowels; the bladder acted. Another ounce of brandy mixed with water was now given. This was shortly vomited, and he expressed himself as feeling better. The pinched appearance, and the character of the pulse, however, remained unchanged. There was frequent sighing, the respirations being now 44 per minute, and gradually becoming more hurried, the pulse weaker, still fluttering and intermittent. He seemed conscious of approaching death. Presently he asked some one to "rub his stomach," an effort at vomiting was made, his face, head, and neck suddenly becarae more livid, the neck being also rigid, and the heart ceased to beat; two or three respiratory efforts were made after the heart's action ceased, the air entering and leaving the chest freely. He died three-quarters of an hour from the time of his seizure as he came down from the surgery apparently well, remaining sensible to the last.

An autopsy was made twenty-four hours after death. The body was fat and well nourished, rigor mortis well marked, considerable hypostatic congestion on posterior parts of the body. There was still slight discoloration at the site of contusion on the right leg. The varicose veins were felt hard and prominent towards the lower and posterior parts of the same leg. On opening the chest the lungs were seen emphysematous on the anterior part, not collapsing. In some parts the pleura was raised in bladders by the air contained beneath: posteriorly there was hypostatic congestion; a few adhesions existed. Nothing abnormal in the appearance of the heart or pericardium. There was a considerable deposit of fat on the surface of the heart; the right side was full of fluid blood (not distended); the left side was empty, moderately contracted, but nothing abnormal was discovered about the heart or its valves; there was no clot, either post-or ante-mortem.

A subsequent examination of the muscular structure of the heart under the microscope showed no fatty degeneration. The inferior vena cava contained a tough clot, greyish-yellow in some parts, beginning above within an inch of the right auricle, extending downwards its whole length, and some distance into the common iliac vein. This clot had all the characters of an ante-mortem one, had con- siderable consistency, and was easily removed entire. The lower part had less of the elastic, fibrous feel than the upper, and broke off on removal. From the common iliac downwards to the lower third of the leg the veins were free from clot till the internal saphena vein in the neighbourhood of the varix was reached, when a firm clot was again encountered, and extended through all the varicose veins, being especially firm in the latter, and in many points closely adherent to the walls of the vessels. The veins throughout the entire varix were rough and reddened in their lining membrane. There was considerable matting together of the cellular tissue in this portion of the limb. The varicose veins were most tortuous, being at several points doubled over each other and requiring considerable care in their dissection, so numerous, knotted, swollen, hard, and twisted were they.

Remarks. - In considering the above facts with reference to the cause of death, the following conclusions are, I think, warranted. The contusion sustained on Jan. 5th on that portion of the leg affected with varix set up sufficient inflammation in the veins to induce a deposit of fibrine from the blood and the formation of a clot in the affected vessels. A portion of this clot probably became detached as he ran down the yard on the day of his death, was floated upwards till it became entangled about the junction of the iliac veins, and upon this comparatively small piece, as a foundation, was quickly deposited the long clot removed from the inferior cava, and by which nearly all moving blood must have been excluded. It may be suggested that death through failure of the supply of blood to the lungs was improbable, as the right side of the heart was found full of blood after death, and no obstruction to its entrance to the lungs existed. But may not this blood have flowed into the right auricle after the heart ceased to contract, and during the two or three inspirations subsequently made? The raising of the chest under such circumstances would exercise considerable suction power. It may be added that the inspection was most carefully made, the cause of death being suspected.

This is the second death I have seen under such circumstances, and I think the general aspect of the patient, and the evidently unsatisfactory nature of the large and deep inspirations, very characteristic of his state and imminent danger. In my first case I failed to diagnose the disease during life. A post-mortem examination only revealed it; but in that case the obstruction was more apparent, being firmly attached to the tricuspid valve, and floating for some distance into the pulmonary artery.

\section{ON THE TREATMENT OF EXOPHTHALMIC GOITRE WITH BELLADONNA.}

BY R. T. SMITH, M.D. LoND., PHYSICLAX TO THE ST. PANCBAS DIRPBYBARY.

Having had to deal with two cases of cardio-thyroid exophthalmos, and having tried for months with very little success the various remedies suggested by Trousseau, Stokes, Walshe, and others, I wish to make an observation on the great relief finally given by the use of belladonna.

CASE 1.-C.S-, aged twenty-four, employed in cartridgemaking, consulted me in February, 1873. She had always had good health before the present illness, which began about nine months ago. The first symptom was a feeling of weakness and tiredness in the eyes in the morning and when at work. About the same time she began to suffer from palpitation, and noticed that the neck was gradually enlarging. For the last six months she has been under medical treatment, taking steel medicine. She was obliged to leave off work in September owing to the general weakness and palpitation, and also to her sight being affected. Objects at a distance of six yards are misty and undefined, while objects within a foot are seen double. The appetite has been very good throughout, and the catamenia perfectly regular.

Present state.-There is an aspect of great distress, and a very wild expression. There is no anæmia. The eyeballs are very much protruded, the right decidedly more so than the left; this is probably the explanation of the diplopia. 